\title{
Ovarian Neoplasm
}

National Cancer Institute

\section{Source}

National Cancer Institute. Ovarian Neoplasm. NCI Thesaurus. Code C4984.

A benign, borderline, or malignant neoplasm involving the ovary. 